\title{
SIMULAÇÃO COMPUTACIONAL DISCRETA EM UMA LINHA DE PRODUÇÃO DE ALIMENTOS EMBUTIDOS
}

\author{
Maurício da Cunha Müller ${ }^{1 *}$, Roguél Dalberto ${ }^{l}$, Thiago Rebelatto ${ }^{l}$, Guilherme Tonini Botassoli ${ }^{2}$, João Carlos Furtado ${ }^{3}$ \\ ${ }^{l}$ CursandoMestrado do Programa de Pós Graduação em Sistemas de Processos Industriais Universidade de Santa Cruz do Sul \\ (UNISC),Santa Cruz do Sul, Brasil \\ ${ }^{2}$ Cursando Graduação em Engenharia Elétrica Universidade de Santa Cruz do Sul(UNISC),Santa Cruz do Sul, Brasil \\ ${ }^{3}$ Programa de Pós-Graduação em Sistemas e Processos Industriais, Universidade de Santa Cruz do Sul (UNISC), Santa Cruz do Sul, \\ Brasil.
}

*E-mail:mauriciomcm@yahoo.com.br

\section{RESUMO}

O propósito deste trabalho é criar alternativas capazes de contribuir para o aumento da produtividade de uma indústria de alimentos embutidos, mediante redução dos tempos operacionais indicados por intermédio de cenários de simulação computacional. Pesquisa bibliométrica realizada junto a portais de periódicos demonstrou a carência desse tipo de estudo de caso com enfoque no segmento industrial de alimentos embutidos. Já como contribuição, essa pesquisa traz a simulação computacional aplicada especificamente em ambiente de processamento de alimentos embutidos, pois existem poucas informações documentadas sobre modificações desse tipo de processo realizadas com o auxílio de softwares de simulação. A metodologia de pesquisa utilizada baseouse em objetivos descritivos e explicativos, com coleta de dados bibliográfica e experimentais, utilizando variáveis quantitativas, buscando assim a obtenção de melhores parâmetros de avaliação. A pesquisa limitou-se à simulação discreta, onde realizou-se a avaliação teórica do processo, sendo possível assim a criação de propostas para modificações do panorama estudado com o intuito de aumentar a produtividade a partir da reorganização do fluxo produtivo. Os resultados foram o aumento da produtividade entre $33 \%$ e $66 \%$, dependendo da modelagem adotada.

Palavras-chave: Simulação computacional. Indústria alimentícia. Produtividade. Alimentos embutidos.

\section{Introdução}

Nas últimas décadas, o setor industrial vem apresentando grande preocupação em otimizar seus processos industriais para que dessa forma torne-se possível diminuir os custos na produção sem diminuir o faturamento e a qualidade. Com os avanços tecnológicos, a simulação computacional se tornou uma ferramenta importante e essencial para melhorar os ambientes de produção e gestão industrial.

As ferramentas computacionais podem ser utilizadas nas mais diversas áreas, entre elas, na indústria alimentícia. Dessa forma, a simulação contribui também para melhorias fabris, como a tradicional fabricação de embutidos, que é basicamente manual, envolvendo pessoas qualificadas e máquinas simples. Aumentar a produtividade e diminuir os desperdícios sem a aquisição de novos maquinários é uma tarefa que demanda cuidados especiais.

A adequação à realidade competitiva pode ser auxiliada por programas computacionais que simulam a produtividade nesse tipo de ambiente. A simulação que auxilia as linhas fabris é gerada em fluxo análogo ao da linha real "in loco". Consiste em elementos fixos com propriedades fiéis, que integradas com elementos dinâmicos existentes na realização de um ambiente de simulação torna-se muito semelhante à realidade, mas com a vantagem de possível adulteração (modelagem). Uma vez o software "carregado" com os dados reais, ele simula o ambiente real promovendo resultados análogos aos resultados in loco, e é a partir desse momento que se pode interagir com esses cenários, modificando-os em busca de melhores resultados finais relacionados com a produtividade de máquinas e pessoas.

Mediante esse cenário, o objetivo deste trabalho é criar alternativas capazes de proporcionar o aumento da produtividade de uma indústria de alimentos embutidos, mediante redução dos tempos operacionais indicados por intermédio de cenários de simulação computacional, utilizando como ferramenta de simulação o software Arena. Para isso, coletou-se os dados necessários para a modelagem computacional que foram inseridos em software de simulação, onde analisou-se o modelo. Foram testadas e apontadas modificações capazes de minimizar tempos e maximizar produção. 

trabalho.

A seguir são fundamentados alguns conceitos chave deste

Os produtos finais da linha de produção em estudo são alimentos embutidos, mais especificamente, mortadelas [1], [2]. Pode-se classificar os embutidos como "alimentos processados", por passarem por diversas operações, como as descritas na definição a seguir: "definem-se como alimentos processados os alimentos que passam por operações mecânicas ou químicas para alterar ou preservar suas características. Um Instituto de Tecnologia dos Alimentos descreve processamento como um ou mais de um conjunto de operações, incluindo lavagem, moagem, mistura, refrigeração, armazenamento, aquecimento, congelamento, filtragem, fermentação, extração, extrusão, centrifugação, fritura, secagem, concentração, pressurização, irradiação, micro-ondas, e embalagem" [3]. Dentre os alimentos embutidos os mais comuns são as mortadelas, presuntos, salsichas, linguiças e morcelas.

As mortadelas são produtos cárneos industrializados, obtidos de uma emulsão das carnes de animais de açougue, acrescidos ou não de toucinho, acrescidos de ingredientes, embutidos em envoltório natural ou artificial, em diferentes formas, e submetidos a tratamento térmico adequado. De acordo com a composição da matéria-prima e das técnicas de fabricação: Carnes de diferentes espécies de animais de açougue, carnes mecanicamente separadas, até o limite máximo de 60\%; miúdos comestíveis de diferentes espécies de animais de açougue (Estômago, Coração, Língua, Fígado, Rins, Miolos), pele e tendões no limite de $10 \%$ (máx.) de gorduras [4]. Dizem [5] e [6] que na massa da mortadela são adicionados aditivos visando à conservação do produto: sal, açúcar, nitrito, nitrato de sódio, emulsificantes e antioxidantes. A produção é dada por etapas, entre elas: trituração da matéria prima (carne), embutimento, grampeamento e cozimento que elimina os patogênicos e deteriorantes [7], [8]. Na metodologia, dá-se maior clareza para as etapas do processo de produção.

A ferramenta base para o desenvolvimento deste trabalho é a simulação. O autor [9] define, de forma pragmática, o processo de modelagem e simulação como uma experimentação computacional, onde são usados modelos de um sistema real ou idealizado para o estudo de problemas reais de natureza complexa, com o objetivo de testar diferentes alternativas operacionais a fim de encontrar e propor melhores formas de operação que visem à otimização do sistema como um todo. Já [10] diz que simulação é a importação da realidade para um ambiente controlado onde se pode estudar o comportamento do mesmo, sob diversas condições, sem riscos físicos e/ou grandes custos envolvidos. Devido a essa flexibilidade e facilidade de uso, comparado a outras técnicas de modelação, o uso de simulação tem se expandido rapidamente, proporcionando incrementos na otimização e eficiência de sistemas.

A utilização da simulação em ambientes manufatureiros traz a possibilidade de obter uma visão geral (macro) do efeito de uma pequena mudança (micro) no sistema, com benefícios como: aumento de produtividade, redução do tempo em processos, redução dos estoques em processo, aumento das taxas de utilização de equipamentos e funcionários, aumento de entregas no tempo certo dos produtos aos clientes, redução das necessidades de capital e garantias de que o projeto do sistema proposto vai operar conforme o esperado [11].

Neste trabalho é utilizada a simulação de eventos discretos e estocásticos, em que, segundo [12], o estado do sistema muda discretamente no tempo - não de forma contínua - e o comportamento não obedece a um padrão determinístico de entradas e saídas, mas aleatório, geralmente caracterizado por uma distribuição probabilística que melhor representa o fenômeno real estudado. A simulação de eventos discretos é uma ferramenta aceita na tomada de decisões de gestão, como a esmagadora literatura sobre o assunto prova [13].

Para o processo de simulação, é necessária a construção de um modelo fiel à realidade. Esses modelos são representações simplificadas das diversas interações entre as partes desse sistema. É uma abstração da realidade, que se aproxima do verdadeiro comportamento do sistema, mas sempre mais simples que o sistema real, sendo, inclusive, utilizada para responder perguntas do tipo "o que ocorre se ..." [11].

Os softwares de simulação são divididos em dois grandes grupos sendo esses, "linguagens de simulação" e "simuladores" [14]. As linguagens de simulação são de natureza mais genéricas, trazem maior liberdade na construção do modelo, porém, exigem grande conhecimento em programação. Já os simuladores, oferecem maior agilidade na construção do modelo e facilidades com utilização de gráficos intuitivos. Por outro lado, observa-se que os simuladores possuem desvantagens como a menor flexibilidade para representar detalhes e restrições de controle na realização de experimentos muito específicos [12].

Existe uma grande variedade de softwares de simulação, cada um podendo apresentar ferramentas exclusivas e vantagens e desvantagens sobre outros. O software de simulação utilizado neste estudo é o Rockwell Arena. Ele apresenta um ambiente gráfico integrado, que contém todos os recursos para modelagem de processos reais, possibilitando assim animação, análise estatística e análise de resultados [15]. No processo de modelagem usando o Arena, o modelo é estruturado e codificado com base na linguagem de simulação SIMAN por meio da seleção dos módulos que contêm as características dos processos a serem modelados. O modelador não precisa necessariamente conhecer esta linguagem para construir um modelo, pois, utilizando os modelos disponibilizados pelo Arena, o usuário pode extrair módulos, posicioná-los e parametrizá-los de acordo com as características observadas no sistema real [16].

O software Arena tem sido utilizado por vários pesquisadores de diversas áreas como mostra [17]: para analisar e projetar um porto; para assegurar se os roteiros para uma barcaça propostos por um programa de otimização são viáveis durante operações fluviais; para auxiliar no desenvolvimento de um modelo de um sistema de Veículo Guiado Automatizado (AGV); para simular vários modos de tráfego; reorganizar lotes; em sistemas de ambulância [18]; entre outros. Já [19],[20],[21] 
mostram o contexto atual entre simulação e otimização, analisando técnicas de otimização embutidas nos softwares de simulação e as implementadas em trabalhos da literatura.

Esse estudo foi realizado em uma fábrica de alimentos embutidos (mortadelas) situada no Rio Grande do Sul, responsável pelo abastecimento de alguns bares, minimercados e supermercados da região central do estado.

Foi observado que na linha de produção, objeto desse estudo, existe matéria-prima parada - ociosa - em meio ao fluxo do processo produtivo, o que fomentou o questionamento: Por que isso acontece? É possível diminuir o tempo produtivo? Aumentar a produtividade modificando assim o cenário atual? Dessa forma, procura-se simular o processo de forma a encontrar respostas e soluções para essas questões.

\section{Metodologia}

Para efetuar a modelagem do processo de fabricação estudado, realizou-se a coleta de dados durante o período de 30 dias juntamente ao processo de fabricação de embutidos (mortadelas) de uma empresa do setor alimentício situada no estado do Rio Grande do Sul. Para efetuar a coleta de dados mensurados (tempo de cada etapa) utilizou-se um cronômetro digital da marca Vollo, modelo VL501.

Após a coleta de dados, observou-se a existência de dois tipos de dados: 1- Dados de grandeza constante, ou seja, onde o tempo de execução não tem variações consideráveis, pois esses processos são realizados através de recursos mecânicos, sendo assim utilizados na simulação sem que haja necessidade de tratamento dos mesmos. 2- Dados de grandeza variáveis, ou seja, onde o tempo de execução possui variações consideráveis. As variações dos tempos operacionais foram mensuradas repetitivamente por 30 vezes cada uma, e, dessa forma, criaramse matrizes contendo-os, conforme tabela 1 de teor exemplificativo.

Tabela 1 - Exemplo de matriz formada com o registro da variação dos tempos cronometrados em minutos.

\begin{tabular}{|l|l|l|l|l|}
\hline 19 & 20 & 18 & 22 & 20 \\
\hline 22 & 22 & 21 & 22 & 19 \\
\hline 21 & 18 & 18 & 17 & 20 \\
\hline 20 & 19 & 22 & 21 & 19 \\
\hline 22 & 22 & 22 & 18 & 18 \\
\hline 19 & 18 & 18 & 22 & 21 \\
\hline
\end{tabular}

Após feito isso, passou-se para etapa de tratamento dos tempos mensurados. Esse processo estatístico é realizado automaticamente través da ferramenta input analyzer contido no software utilizado (Arena) e que gera as curvas matemáticas peculiares de cada etapa do processo, conforme gráfico de teor exemplificativo da figura 1.

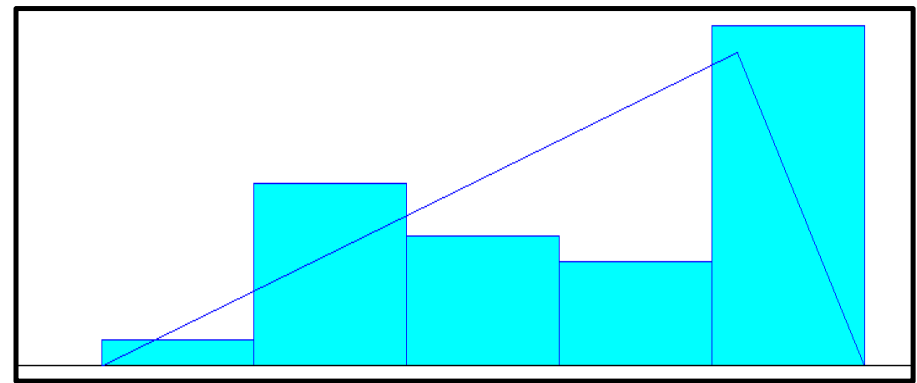

Figura 1 - Exemplo de curva matemática referente aos tempos distintos cronometrados em minutos.

Realizou-se o tratamento e modelagem dos dados obtidos no software Arena, onde se gerou o fluxo produtivo básico fiel ao real. Esse fluxo é composto por todas as etapas da fabricação, sendo elas: entrada de matéria prima, desembalar, deposição, transporte, trituração, transporte, ensacamento, grampeamento, transporte, cozimento, conforme fluxo de teor exemplificativo da figura 2. Cada etapa do processo produtivo está inserida em um módulo com finalidade específica e análoga a realidade in loco.

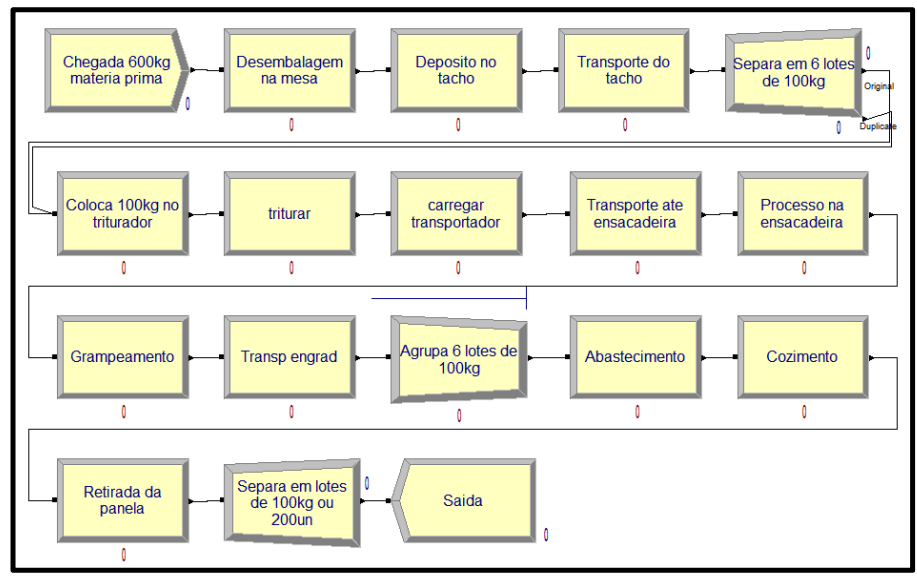

Figura 2 - Exemplo do cenário modelado do fluxo produtivo da linha operante

Após a simulação do fluxo produtivo real, foram executadas simulações de teste com o intuito de modificar e melhorar a produtividade, e para isso, foram alterados - no software ARENA - o posicionamento dos funcionários e dos equipamentos envolvidos no processo, obtendo assim novos resultados.

Os novos resultados obtidos foram comparados com os anteriores, o que estimulou a argumentação de viabilidade ou não de modificações na linha produtiva.

\section{Resultados e discussões}




\subsection{Inserção e simulação dos dados in loco}

Condescendentemente ao descrito no item metodologia, obteve-se os dados mapeados no estudo in loco e descritos a seguir.

A entrada de matéria prima ocorre em lotes de $600 \mathrm{~kg}$, a cada 2,88 horas ou 173 min, totalizando assim 3 lotes ou $1800 \mathrm{~kg}$ produzidos por dia ( 9 horas).

O funcionário 1 desembala toda a matéria prima sobre uma mesa, cuja variação dos tempos cronometrados em minutos são identificados na Tabela 2

Tabela 2- Registro da variação dos tempos cronometrados em minutos para a abertura das embalagens do lote de matéria prima.

\begin{tabular}{|l|l|l|l|l|}
\hline 19 & 20 & 18 & 22 & 20 \\
\hline 22 & 22 & 21 & 22 & 19 \\
\hline 21 & 18 & 18 & 17 & 20 \\
\hline 20 & 19 & 22 & 21 & 19 \\
\hline 22 & 22 & 22 & 18 & 18 \\
\hline 19 & 18 & 18 & 22 & 21 \\
\hline
\end{tabular}

Efetuou-se o tratamento da variação dos tempos cronometrados durante a etapa de abertura de embalagem e, utilizando a ferramenta input analyzer, foi gerada uma curva triangular de expressão "TRIA(16.5, 21.5, 22.5)" conforme Figura 3.

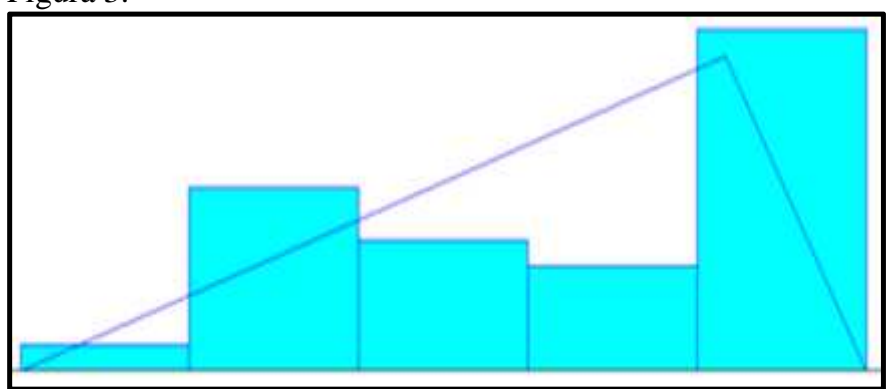

Figura 3 - Curva resultante dos tempos do processo de abertura das embalagen do lote de matéria prima

Após desembalar, o funcionário 1 move a matéria prima para um recipiente de inox que serve como transportador, cuja variação dos tempos cronometrados em minutos são identificados na Tabela 3.

Tabela 3- Registro da variação dos tempos cronometrados em minutos para a deposição do lote de matéria prima no recipiente de inox.

\begin{tabular}{|l|l|l|l|l|}
\hline 5 & 4 & 5 & 5 & 6 \\
\hline 4 & 4 & 5 & 4 & 4 \\
\hline 4 & 5 & 6 & 6 & 5 \\
\hline 6 & 6 & 4 & 3 & 5 \\
\hline 4 & 5 & 4 & 4 & 4 \\
\hline
\end{tabular}

Efetuou-se o tratamento da variação dos tempos cronometrados durante a movimentação do recipiente de inox utilizando a ferramenta input analyzer, gerando uma curva Erlang de expressão " $2.5+\operatorname{ERLA}(0.363,6)$ " conforme figura 4.

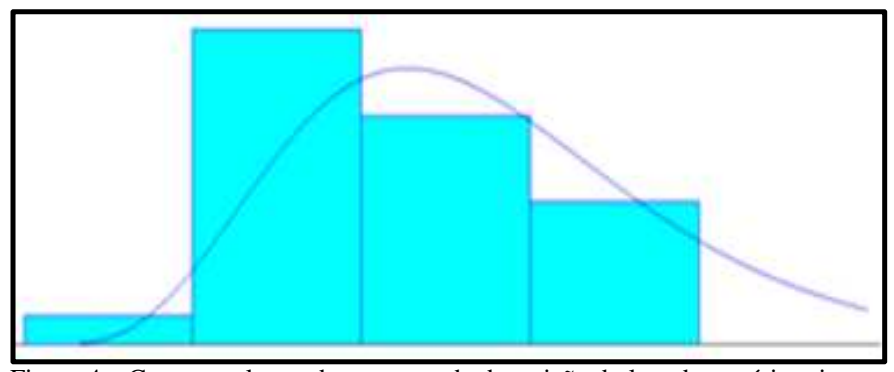

Figura 4 - Curva resultante do processo de deposição do lote de matéria prima no recipiente de inox.

Após depositar o lote de matéria prima desembalada no recipiente de inox - transportador - o funcionário 1 transporta o mesmo até uma balança situada em frente do triturador utilizando para este processo o tempo constante de $1 \mathrm{~min}$.

Após o transporte da matéria prima até a balança, o funcionário 2 separa e move porções de $100 \mathrm{~kg}$ de matéria prima do recipiente de inox ao triturador, utilizando uma pá, cuja variação dos tempos cronometrados em minutos são identificados na Tabela4.

Tabela 4 - Registro da variação dos tempos cronometrados em minutos para a deposição dos $100 \mathrm{Kg}$ de matéria prima no triturador.

\begin{tabular}{|c|c|c|c|c|}
\hline 5 & 4 & 4 & 4 & 5 \\
\hline 4 & 4 & 4 & 4 & 5 \\
\hline 5 & 4 & 5 & 5 & 4 \\
\hline 5 & 6 & 5 & 6 & 6 \\
\hline 4 & 4 & 4 & 5 & 4 \\
\hline
\end{tabular}

Efetuou-se o tratamento da variação dos tempos cronometrados durante a separação e movimentação das porções de matéria prima utilizando a ferramenta input analyzer, gerando uma curva triangular de expressão "TRIA(3.5, 3.8, 6.5)" conforme figura 5 .

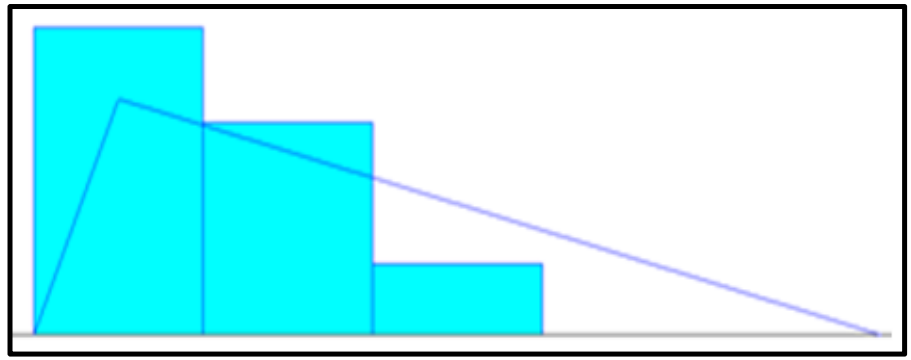

Figura 5 - Curva resultante do processo de deposição dos $100 \mathrm{Kg}$ de matéria prima no triturador. 
Após a movimentação das porções começa a trituração do lote. A capacidade de processamento do triturador é de $100 \mathrm{~kg}$ o mesmo leva tempo constante de 10 min para realizar a trituração resultando em um tempo de 60 minutos para triturar todo o lote de $600 \mathrm{~kg}$ de matéria prima. Nesta etapa o recipiente de inox fica aguardando até que seja utilizada toda a sua carga de $600 \mathrm{~kg}$ para então retornar ao início do processo.

O funcionário 2 descarrega os $100 \mathrm{~kg}$ de matéria prima trituradas dentro de outro transportador de inox - com o auxílio de uma pá de inox - cuja variação dos tempos cronometrados em minutos são identificados naTabela5.

Tabela 5- Registro da variação dos tempos cronometrados em minutos para a descarga dos $100 \mathrm{Kg}$ de matéria prima do triturador.

\begin{tabular}{|l|l|l|l|l|}
\hline 3 & 3 & 2 & 4 & 3 \\
\hline 2 & 3 & 3 & 5 & 4 \\
\hline 2 & 3 & 2 & 5 & 5 \\
\hline 3 & 3 & 3 & 4 & 3 \\
\hline 3 & 4 & 4 & 4 & 5 \\
\hline
\end{tabular}

Efetuou-se o tratamento da variação dos tempos cronometrados durante a descarga do triturados utilizando-se a ferramenta input analyzer, gerando uma curva Gamma de expressão " $1.5+\operatorname{GAMM}(0.558,3.4)$ " conforme figura 6 .

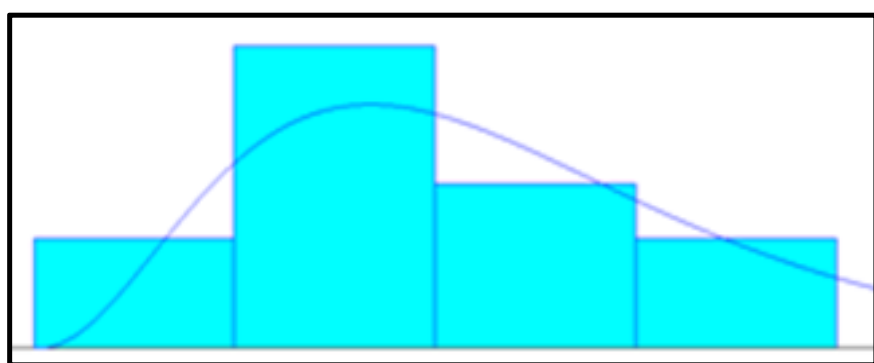

Figura 6 - Curva resultante do processo de retirada dos $100 \mathrm{Kg}$ de matéria prima do triturador.

Após a retirada do triturador, os $100 \mathrm{~kg}$ de matéria prima são transportados até a ensacadora, sob tempo constante de 1,5 min. A ensacadora comporta apenas os $100 \mathrm{~kg}$ de matéria prima triturada, produzindo a partir deste volume 200 unidades do produto com o peso de $0,5 \mathrm{~kg}$ cada. A ensacadora é operada pelo funcionário 3 , cuja variação dos tempos cronometrado sem minutos referentes a essa operação são identificados na Tabela 6.

Tabela 6 - Registro da variação dos tempos cronometrados em minutos para o ensacamento das mortadelas.

\begin{tabular}{|l|l|l|l|l|}
\hline 5 & 4 & 5 & 5 & 4 \\
\hline 3 & 3 & 6 & 3 & 3 \\
\hline 3 & 3 & 4 & 4 & 4 \\
\hline 3 & 5 & 5 & 5 & 4 \\
\hline 4 & 4 & 4 & 4 & 4 \\
\hline
\end{tabular}

Efetuou-se o tratamento da variação dos tempos cronometrados durante o ensacamento, utilizando a ferramenta input analyzer, gerando uma curva Beta de expressão " $2.5+4 *$ $\operatorname{BETA}(1.96,3.1)$ "conforme figura 7.

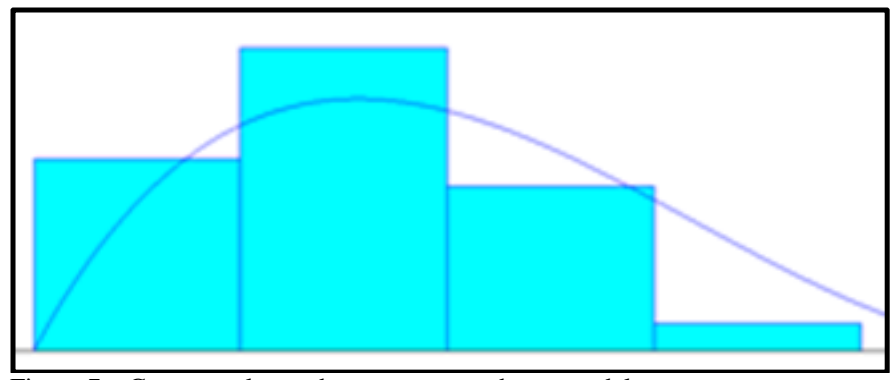

Figura 7 - Curva resultante do ensacamento das mortadelas

Ao sair da ensacadora os $100 \mathrm{~kg}$ de matéria prima transformadas em mortadelas são grampeadas com o auxílio de uma grampeadeira, uma a uma, pelo funcionário 4 cuja variação dos tempos cronometrados em minutos são identificados na Tabela 7.

Tabela 7 - Registro da variação dos tempos cronometrados em minutos para o grampeamento das mortadelas.

\begin{tabular}{|c|c|c|c|c|}
\hline para o grampeamento das mortadelas. \\
\hline 4 & 5 & 3 & 3 & 3 \\
\hline 4 & 5 & 3 & 5 & 3 \\
\hline 3 & 3 & 4 & 5 & 3 \\
\hline 3 & 4 & 4 & 3 & 3 \\
\hline 3 & 4 & 4 & 4 & 4 \\
\hline
\end{tabular}

Efetuou-se o tratamento da variação dos tempos cronometrados durante o grampeamento utilizando-se a ferramenta input analyzer, gerando uma curva Beta de expressão “ $2.5+3 * \operatorname{BETA}(1.12,1.72)$ "conforme figura 8 .

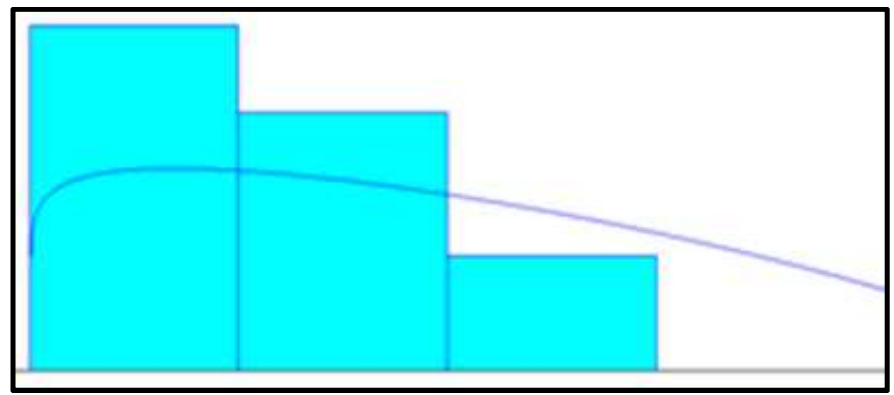

Figura 8 - Curva resultante do processo de grampeamento das mortadelas

O Lote de $100 \mathrm{~kg}$ de matéria prima, já transformados em mortadelas, caem dentro de um recipiente de plástico engradado - então o funcionário 1 transporta o engradado de plástico contendo as mortadelas até os varais da espera de 
cozimento cuja variação dos tempos cronometrados em minutos são identificados na Tabela 8.

Tabela 8 - Registro da variação dos tempos cronometrados em minutos para o deslocamento do engradado até o setor de espera para o cozimento.

\begin{tabular}{|c|c|c|c|c|}
\hline 2 & 1 & 1 & 2 & 1 \\
\hline 1 & 2 & 2 & 1 & 2 \\
\hline 1,5 & 2 & 1 & 1,5 & 2,5 \\
\hline 2 & 2 & 1 & 2,5 & 2 \\
\hline 1 & 1 & 1 & 2 & 2 \\
\hline
\end{tabular}

Efetuou-se o tratamento da variação dos tempos cronometrados durante o transporte do engradado utilizando-se a ferramenta input analyzer, gerando uma curva Gamma de expressão “0.999 + GAMM(1.99, 0.302)"conforme figura 9.

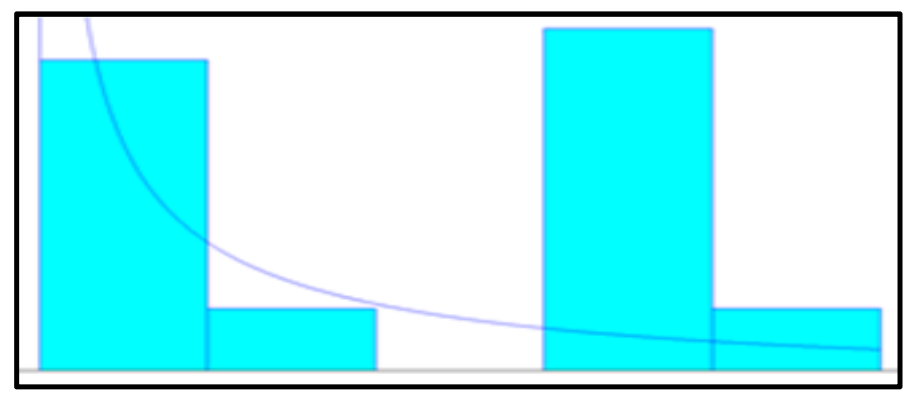

Figura 9 - Curva resultante do processo de deslocamento até o setor de esper para o cozimento.

A batelada de cozimento ocorre quando existem 1200 mortadelas nos varais da espera, ou seja, $600 \mathrm{~kg}$ de matéria-prima, então ao chegar a este número o funcionário 5 posta as 1200 mortadelas (ou $600 \mathrm{~kg}$ de matéria prima) na panela de cozimento com o tempo constante de $10 \mathrm{~min}$.

O cozimento demora um tempo constante de 50min, e é acompanhado constantemente pelo funcionário 5 .

Após o cozimento o funcionário 5 retira as mortadelas do interior da panela e as condiciona em um varal de saída cuja variação dos tempos cronometrados em minutos referentes a essa operação são identificados na Tabela 9.

Tabela 9 - Registro da variação dos tempos cronometrados em minutos para o condicionamento das mortadelas nos varais de saída.

\begin{tabular}{|l|l|l|l|l|}
\hline 20 & 22 & 20 & 21 & 23 \\
\hline 21 & 23 & 22 & 22 & 21 \\
\hline 20 & 21 & 22 & 23 & 24 \\
\hline 20 & 19 & 20 & 20 & 23 \\
\hline 19 & 19 & 22 & 22 & 20 \\
\hline
\end{tabular}

Efetuou-se o tratamento da variação dos tempos cronometrados durante o condicionamento no varal utilizando-se a ferramenta input analyzer, gerando uma curva Beta de expressão " $18.5+6 * \operatorname{BETA}(1.47,1.85)$ figura 10 .

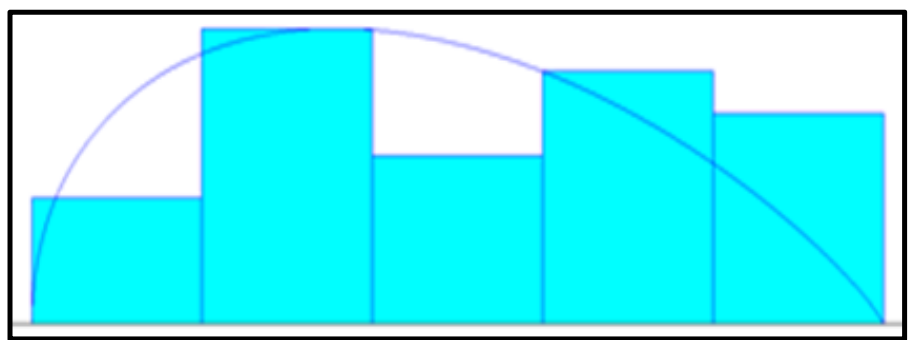

Figura 10 - Curva resultante do processo de condicionamento das mortadelas nos varais de saída.

Existem dois processos externos, com tempos de 0,6 min e outro de 5 min cada, com as finalidades respectivas de limpeza dos postos de trabalho e repouso dos funcionários.

Após a tomada dos tempos, foi montado o fluxo produtivo no software Arena e que pode ser visualizado na figura 11.

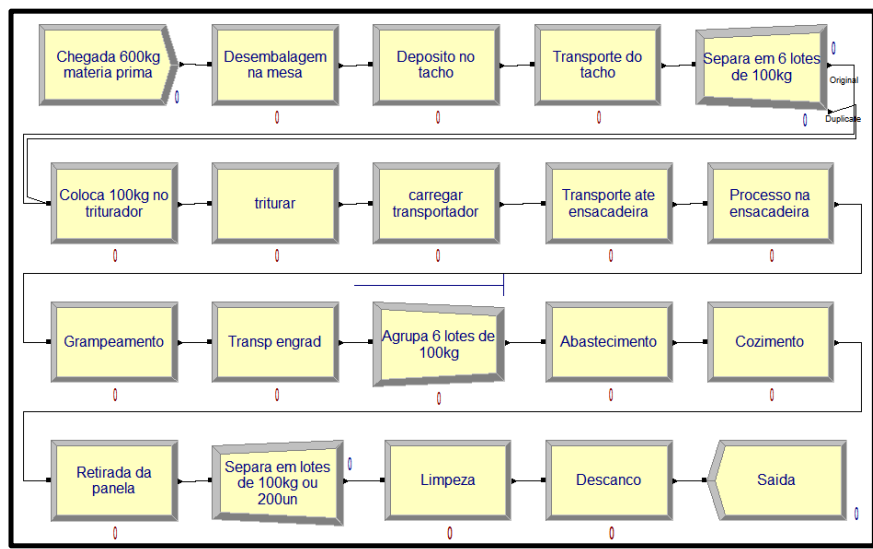

Figura 11 - Fluxo produtivo in loco.

Cabe salientar que no processo produtivo in loco são produzidas $1800 \mathrm{~kg}$ de mortadela em 9 horas.

Após realizar a modelagem conforme o processo de fabricação real - in loco, realizou-se a etapa de simulação. Os dados coletados foram replicados dez vezes para gerar maior confiabilidade de análise na avaliação dos resultados obtidos. Através da simulação no software arena, detectou-se que o tempo médio de execução do processo situava-se na casa de 540 minutos para a produção de $1800 \mathrm{~kg}$ do produto final, comparando com o tempo médio coletado in loco, sendo este de 546 minutos, onde percebeu-se uma diferença na ordem de $1,09 \%$ para mais, porém, por se tratar de um valor médio onde a diferença não é considerada expressiva utilizou-se os dados coletados in loco validando assim o modelo de simulação.

Com base nos resultados gerados a partir da simulação, iniciou-se a identificação de possíveis etapas responsáveis pelo acúmulo de matéria prima, momento em que se observou a 
existência dessa situação na entrada geral da produção e no triturador

\subsection{Simulação das possíveis alternativas para aumento produtivo}

Procurando atender o objetivo deste trabalho, foram desenvolvidas duas propostas de auxílio ao aumento da produção mediante redução tempo de fabricação. Uma que não necessita novos equipamentos e outra que necessita. Para facilitar a visualização das modificações dentro da linha, a Tabela10 mostra as máquinas e os funcionários.

Tabela 10 - Recursos que a linha de produção necessita.

\begin{tabular}{|l|l|}
\hline Funcionários & Máquinas \\
\hline Funcionário 1 & Desembalar, Transportador \\
\hline Funcionário 2 & Triturador \\
\hline Funcionário 3 & Ensacadora \\
\hline Funcionário 4 & Grampeadeira \\
\hline Funcionário 5 & Panela de cozimento \\
\hline
\end{tabular}

\subsubsection{Simulação da primeira alternativa proposta}

Nesta simulação modificou-se a chegada de matéria prima, que ao invés de chegar em batelada de $600 \mathrm{~kg}$, passa a chegar em lotes de $100 \mathrm{~kg}$ a cada $15 \mathrm{~min}$. Dessa forma, após rodar a simulação, o ARENA apontou um aumento de $33 \%$ na produtividade, passando de $1800 \mathrm{~kg}$ dia para $2400 \mathrm{~kg}$ dia produzidos durante as 9 horas trabalhadas.

A razão desse aumento é o fato do triturador possuir a capacidade de triturar $100 \mathrm{~kg}$ a cada $10 \mathrm{~min}$, sendo assim, inexiste filas de espera em frente a esta máquina.

Tabela 11 - Ganho produtivo na primeira alternativa proposta

\begin{tabular}{|c|c|c|}
\hline In loco $(\mathrm{kg})$ & $1^{\mathrm{a}}$ alternativa proposta $(\mathrm{kg})$ & Ganho $(\%)$ \\
\hline 1800 & 2400 & $33 \%$ \\
\hline
\end{tabular}

\subsubsection{Simulação da segunda alternativa proposta}

Nesta simulação, a matéria-prima chega em bateladas de $600 \mathrm{~kg}$ a cada 1 hora e instalou-se mais um triturador no processo.

Dessa forma, após rodar a simulação, o ARENA apontou um aumento de $66 \%$ na produtividade, passando de $1800 \mathrm{~kg}$ dia para $3000 \mathrm{~kg}$ dia. A razão desse aumento é o fato de inexistir filas de espera em frente a esta máquina.

Tabela 12 - Ganho produtivo na segunda alternativa proposta

\begin{tabular}{|c|c|c|}
\hline In loco $(\mathrm{kg})$ & $2^{\text {a }}$ alternativa proposta $(\mathrm{kg})$ & Ganho $(\%)$ \\
\hline 1800 & 3000 & $66 \%$ \\
\hline
\end{tabular}

\subsubsection{Comparação entre os três processos}

Tabela 13 - Comparação de ganho entre os processos apresentados

\begin{tabular}{|c|c|}
\hline Processos & Produtividade em 9 Horas \\
\hline In Loco & $1800 \mathrm{~kg}$ \\
\hline $1^{\text {a }}$ alternativa proposta & $2400 \mathrm{~kg}$ \\
\hline $2^{\text {a }}$ alternativa proposta & $3000 \mathrm{~kg}$ \\
\hline
\end{tabular}

\section{Conclusões}

A simulação de processos com o software Arena demonstrou-se muito eficiente apontando claramente que é possível modificar o cenário atual - in loco - melhorando-o, obtendo assim, significativos aumentos produtivos em função destas modificações.

A primeira proposta demonstra, que ao mudar a disposição e o tempo de chegada da matéria de $600 \mathrm{~kg}$ a cada 173 minutos para $100 \mathrm{~kg}$ cada $15 \mathrm{~min}$, resulta em um aumento de produtividade na casa de $33 \%$ durante a jornada de trabalho de 9 horas sem que haja impactos financeiros relacionados a investimentos no processo produtivo.

A segunda alternativa demonstra a implementação de mais um triturador no processo produtivo, o que possibilita manter a chegada de matéria prima em lotes de $600 \mathrm{~kg}$ a cada hora gerando assim, aumento de produtividade que chega ao patamar de $66 \%$.

Desta forma, conclui-se que ambas as propostas simuladas, são capazes de aumentar a produção de alimentos embutidos, ficando assim a critério da direção da indústria alimentícia na qual o processo foi estudado, analisar o que melhor atende as necessidades atuais.

\section{Agradecimentos}

Os autores agradecem à empresa fabricante de alimentos embutidos pela confiança e a oportunidade de realização desse projeto.

\section{DISCRETE COMPUTER SIMULATION IN A PROCESSED MEATS PRODUCTION LINE}

ABSTRACT: The purpose of this study is to create alternatives that can contribute to an increase of productivity of an industry of processed meats by reducing operating times indicated by computer simulation. Bibliometric research conducted with websites of scientific articles demonstrated the lack of this type of case study focusing on the industrial segment of processed meats. As a contribution, this research brings computer simulation specifically applied in the processed meats environment because there is little documented information about 
modifications of such processes carried out with the aid of simulation software. The research methodology used was based on descriptive and explanatory purposes, with experimental and theoretical data collection, using quantitative variables, thereby seeking to obtain better evaluation parameters. The research was limited to discrete simulation, in which the theoretical evaluation of the process was held, thus making it possible to create suggestions for modifications of the situations studied in order to increase productivity from the reorganization of the production flow. Results were increased productivity between $33 \%$ and $66 \%$, depending on the modeling adopted.

Keywords: Computer simulation. Food industry. Productivity. Processed Meats.

\section{Referências}

[1] LEDERER, J. Enciclopédia Moderna de Higiene Alimentar. São Paulo: Editora Manole Dois Ltda, 1991.

[2] ROCCO, S. C. Embutidos, Frios e Defumados. Brasília: Embrapa - SPI, 1996.

[3] WEAVER, C. M. Processed foods: contributions to nutrition. Am J Clin Nutr, v. 99, n. 6, p. 1525-1542. 2014. Disponível em http://ajen.nutrition.org/content/99/6/1525.long\#ref-1. Acesso em: 27/03/2015.

[4] BRASIL. Instrução Normativa $N^{\circ}$ 4, de 31 de março de 2000. Diário Oficial da União de 05/04/2000, Seção 1, Página 6. Disponível em:http://extranet.agricultura.gov.br/sislegis-

consulta/consultarLegislacao.dooperacao=visualizar\&id=7778. Acesso em $27 / 03 / 2015$

[5] FREY, W. Fabricacion Fiable de Embutidos. Zaragoza (Espanha): Editora ACRIBIA - AS, 1983

[6] BASSOUL, E.; BRUNO, P.; KRITZ, S. Nutrição e Dietética. Rio de Janeiro: Editora SENAC Nacional, 1998.

[7] ORNELlAS, L. H. Técnica Dietética. $7^{\mathrm{a}}$ Ed. São Paulo: Editora Atheneu, 2001.

[8] DOMENE, S. M. A. Técnica Dietética. Rio de Janeiro: Guanabara Koogan, 2011.

[9] CARVALHO, L. S. D. Modelagem e Simulação: Poderosa Ferramenta para a Otimização de Operações Logísticas. Salvador. 2013.

[10] COSTA, F. M. D. Construção de modelo de simulação de sistema puxado de produção para melhorias de eficiência. Repositóriun, 2011.

[11] ALBERTI, R. A. et al. Uso de simulação computacional para avaliação de cenários produtivos em empresa de acessórios para motociclistas. III Congresso Brasileiro de Engenharia de Produção - CONBREPRO. Ponta Grossa - PR. 2013.

[12] SAKURADA, N.; MIYAKE, D. I. Aplicação de simuladores de eventos discretos no processo de modelagem de sistemas de operações de serviços. Revista Gestão e Produção, v.16, n.1, p.24-43, São Carlos, jan./mar. 2009.
[13] CHEMWENO, P.; et al. Discrete event simulation case study: Diagnostic path for stroke patients in a stroke unit. Simulation Modelling Practice and Theory, Volume 48, November 2014, Pages 45-57.

[14] LAW, A. M.; KELTON, W. D. Simulation modeling and analysis. Nova York: Editora McGraw-Hill, 1991.

[15] NETO, A. N. R; PINTO, 1. R. Template do programa Arena para simulação das operações de carregamento e transporte em minas a céu aberto. Revista Escola de Minas, v.57, n.1, p.65-69, Ouro Preto, jan./mar. 2004.

[16] Botassoli, G. T.; Alberti, R. A.; FuRTAdO, J. C. Métodos heurísticos na otimização de parâmetros através de simulação. XI Simpósio de Engenharia de Produção - SIMPEP. Bauru - SP. 2014.

[17] KAMRANI, M.; et al. Traffic simulation of two adjacent un signalized Tjunctions during rush hours using Arena Software. Simulation Modelling Practice and Theory, Volume 49, December 2014, Pages 167-179.

[18] PINTO, L.R.; SILVA, P.M.S.; YOUNG, T.P.A generic method to develop simulation models for ambulance systems. Simulation Modelling Practice and Theory, Volume 51, February 2015, Pages 170-183.

[19] FU, M. Optimization for Simulation: Theory vs. Practice. INFORMS Journal on Computing, Vol. 14, No. 3, Summer 2002, pp. 192-215.

[20] WALES, J.; Marinov, M. Simulation Modelling. Practice and Theory Simulation Modelling Practice and Theory v.52 p.52-77, 2015.

[21] BRÜGMANN, J.; SCHRECKENBERG, M.; LUTHER. W. A verifiable simulation model for real-world microscopic traffic. Simulation Modelling Practice and Theory, v. 48 p.58-92, 2014. 